\title{
Brain Temperature Alterations and the Retention of Visual Pattern Discriminations in Pigeons
}

\begin{abstract}
OLSEN, C. A., J. D. DELIUS AND G. R. J. HOCKEY. Brain temperature alterations and the retention of visual pattern discriminations in pigeons. PHYSIOL. BEHAV. 13(2) 257-260, 1974. - Pigeons were taught visual discriminations. Immediately after they had reached criterion their forebrain was either left untreated or heated (by $\left.\approx 1^{\circ} \mathrm{C}\right)$ or cooled (by $\left.\approx 2^{\circ} \mathrm{C}\right)$ for $30 \mathrm{~min}$, with water flowing through a chronically implanted cannula system. The effects of the treatments on retention were assessed in retraining sessions. Both brain temperature alterations led to slight saving scores and marked, significant response latency advantages, compared with the control treatment.
\end{abstract}

Brain temperature Memory Pigeon Visual discrimination

EXPERIMENTS involving transitory chemical and physical treatments of the brain of animals after they have learned some specific task have contributed much towards the current understanding of the material bases of memory [3]. Brain tissue temperature alteration is one such treatment that has been considered but hitherto experiments have had to rely on heating or, more often, cooling the whole animal with the consequent difficulty in ascribing the various effects on subsequent retention performance specifically to the heating or cooling of neural tissue (e.g., $[1,2,4,7$, 14]). The same problem applies to studies which have depended on body temperature changes occurring naturally during annual or diurnal cycles (e.g., $[5,9,11])$ where there is also the possibility that effects on memory may be due to other physiological rhythms that run concurrently with the temperature cycles. Not surprisingly, the picture that emerges from all these studies is less than clear, and we still do not know what effects cooling and heating of brain tissue has on memory. In this report we describe preliminary results obtained with a simple technique that virtually restricts the temperature alterations to the brain itself. The results indicate that the performance during retention tests of a visual discrimination task is affected by brief treatments of this type administered immediately after acquisition.

\section{METHOD}

\section{Animals and Surgery}

Four pigeons (Columba livia) of local racing stock, at least 2 years old and of unknown sex, were used in the experiment. Under Equithesin anesthesia (intra-muscular, $0.25 \mathrm{ml} / 100 \mathrm{~g}$ body weight) and while the head was held in a stereotaxic instrument [8] they were equipped with a set of 3 cannulas traversing the brain (Fig. 1). These were made of stainless steel tubing, $0.8 \mathrm{~mm}$ outer diameter and had closed, conically-sharpened tips. Using guide tubes they were driven by percussion through the bone and brain until they emerged at the opposite side. With reference to skull landmarks exposed by skin incisions, one cannula was placed transversally through the head at the same anterio-posterio plane as the anterior comissure and about $1 \mathrm{~mm}$ above it (coordinates A 8, H 8.5 according to [8]), coursing mainly through the paleostriatum. The other two entered the forebrain hemispheres just above and behind the olfactory bulbs (A 14, H 10, L 2), and coursed obliquely laterally and posteriorly leaving the forebrain at their caudal pole, laterally from the cerebellum (A 1, H 12, L 4). For most of their length these latter cannulas coursed through the hyperstriatum and the neostriatum. After their sharpened ends had been cut to length and deburred they were interconnected with small lengths of closely fitting polythene

\footnotetext{
${ }^{1}$ Present address: Dept of Psychology, University of Newcastle, Newcastle, England.
} 


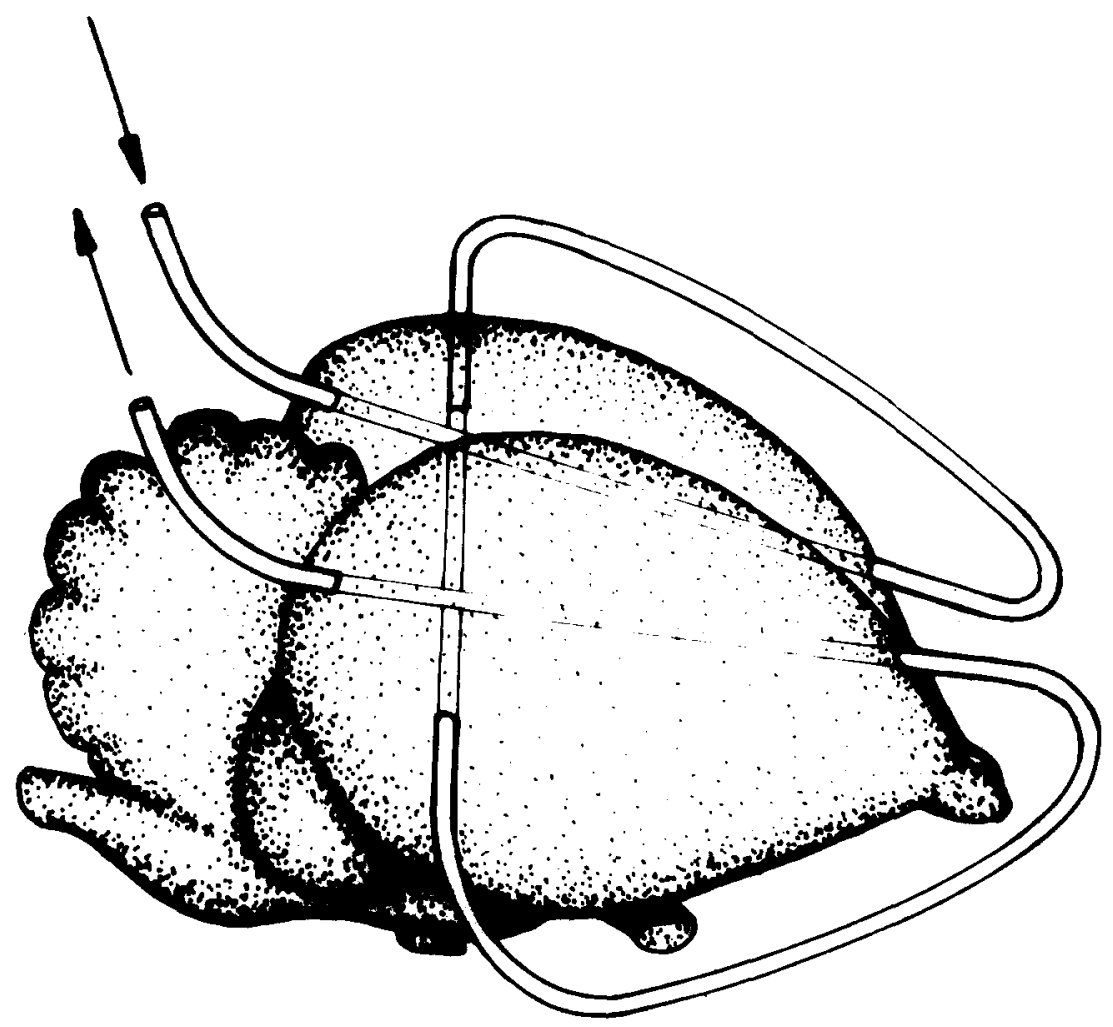

FIG. 1. Schematic drawing of a pigeon brain with the cannula arrangement used.

tubing. The ends of the transversal cannula were each connected to the anterior ends of the longitudinal cannulas. The posterior ends of the latter were bent upwards and cemented to the skull, previously pitted with a dental drill, using acrylic cement; these served as inlet and outlet for water. The wounds were liberally sprinkled with sulphadimidine and closed with a few stitches. All operations were successful and none of the birds showed any ill-effects after they had recovered from anesthesia. Behaviour procedures began one week after the operation.

\section{Histology}

After the termination of the experiment the animals were sacrificed, their brains perfused through the carotids and removed after withdrawal of the cannulas. The location of the cannulas was ascertained by examination of conventionally prepared cresyl violet stained frozen sections. It was closely similar for all four birds. Apart from the actual cannula tracks no tissue damage could be detected: no major blood vessels had been damaged and no accumulation of glia could be observed. The appearance of the tissue adjacent to the cannulas tracks was in every respect identical to that of tissue well away from them.

\section{Brain Cooling and Heating}

The animals were restrained with a cloth jacket. Water at laboratory tap pressure was heated to either $20^{\circ} \mathrm{C}$ or $44^{\circ} \mathrm{C}$ by passing it through a copper tubing serpentine immersed in a thermostatically controlled water bath. A short length of polythene tubing conducted the water to the inlet cannula on the bird's head and a similar length of tubing collected the water from the outlet cannula in a vessel. The flow rate was nearly constant, approximately 1 litre of water being passed through the system during the $30 \mathrm{~min}$ of temperature treatment. For the normal, control condition the birds were restrained and connected in the same way for the same length of time, but no water was passed through the cannulas.

The effective cooling and heating of neural tissue was assessed by equipping an additional pigeon with a cannula system as described previously and passing water through the brain while the animal continued under anesthesia. Through trephine holes in the skull a calibrated thermistor was stereotaxically lowered to 10 different sites evenly distributed through the telencephalon and the anterior diencephalon and lying between approximately 1 and $6 \mathrm{~mm}$ from the nearest cannula. The temperatures recorded stabilized after about $3-5 \mathrm{~min}$ of water flow. Water at $20^{\circ} \mathrm{C}$ lowered the temperature of the sites sampled by an average of $2.3^{\circ} \mathrm{C}$ (range $5.8^{\circ}-0.5^{\circ} \mathrm{C}$ ) $44^{\circ} \mathrm{C}$ increased it by an average of $1.1^{\circ} \mathrm{C}$ (range $2.2^{\circ}-0.4^{\circ} \mathrm{C}$ ). There was evidence, as one might expect, of marked temperature gradients away from the cannulas, but it was less steep than that seen in the same animal after it had been killed with an overdose of Nembutal. This was probably due to heat transfer through the flow of blood. Rectal temperature, as checked with a thermometer, was unaffected by the treatments. Thus, a large portion of the forebrain was effectively heated or cooled, if not evenly so, without measurably affecting body temperature. 
The temperature alterations incidentally markedly affected the ongoing behaviour of the animals. During brain cooling we observed an obvious decrease in activity and responsiveness. During brain heating on the other hand there was a clear increase of activity and attentiveness. Thermoregulatory behaviour (shivering and panting) was noticed only on a few occasions and was not particularly marked (see also [13]).

\section{Behavioural A pparatus}

A standard, two-key pigeon Skinner box was used. In line projectors displayed one of three patterned stimulus pairs on the keys. Standard relay equipment programmed the sequence and duration of events. A printout counter recorded response latencies to $0.2 \mathrm{sec}$ precision, the correct or incorrect nature of the response and which of the two keys had been operated.

\section{Behavioural Procedures}

The birds were deprived to $80 \%$ of their weight and rewarded with 4 sec access to food throughout the experiment. They were trained to keypeck on blank keys. Each bird was then taught to discriminate pairs of stimuli according to the schedule of Table 1. Daily sessions consisting of 30 trials were given. Within each trial the sequence of events was as follows. The stimuli were projected on the keys and remained on until the bird pecked one of the keys. If the animal pecked the key bearing the correct stimulus it was rewarded and the next trial began immediately afterwards. If the response was to the incorrect stimulus, the keys and the houselight went off for $10 \mathrm{sec}$ before the next trial began. Pecks at the darkened keys reinitiated the time-out period. Normally the key on which the correct stimulus was displayed was determined by a Gellerman semi-random sequence, but if a bird showed a persistent side preference, a correction procedure was temporarily introduced during which only correct responses lead to side reversal of stimuli according to the Gellerman sequence. This, however, did not operate during the acquisition of critical data. When a bird reached criterion that is emitted 8 successive correct responses the session was terminated and within $3 \mathrm{~min}$ its brain was either cooled, heated or left normal for $30 \mathrm{~min}$, according to the schedule of Table 1 by the procedure described earlier. The next day the bird was given a relearning session with the same pair of stimuli, leasting until it had again reached the criterion of 8 successive correct trials. The whole procedure was repeated for each bird with two further pairs of stimuli and brain temperature alterations according to the schedule shown in Table 1. Note that the schedule for the first three birds is arranged according to a latin square. The schedule for Bird 4 was the same as for Bird 2, but with the significance of the stimuli reversed. This provided a control for possible effects due to spontaneous stimulus preferences.

\section{RESULTS}

The pigeons took between 67 and 173 trials to reach and complete the learning criterion for the various visual discriminations. Relearning to the same criterion after the various treatments took between 8 and 30 trials. Mean savings scores were greater after both the cooling and heating treatments ( $89 \%$ in each case) than after the normal treatment $(83 \%)$, but the differences were not significant. A
TABLE 1

TRAINING AND TREATMENT SCHEDULES

\begin{tabular}{|c|c|c|c|}
\hline & \multicolumn{3}{|c|}{ Stimulus Pairs } \\
\hline & $1 \mathrm{st}$ & 2nd & 3rd \\
\hline Bird 1 & cooling & normal & heating \\
\hline Bird 2 & normal & heating & cooling \\
\hline Bird 3 & heating & cooling & normal \\
\hline Bird 4 & normal & heating & cooling \\
\hline
\end{tabular}

TABLE 2

CHANGES IN MEDIAN RESPONSE LATENCY FROM BEFORE TREATMENT TO RELEARNING (SEC)

Treatment
Cooling

\begin{tabular}{lccc}
\hline & & & \\
Bird 1 & +0.9 & -0.7 & +0.2 \\
Bird 2 & +0.2 & -0.5 & 0 \\
Bird 3 & +2.2 & +0.2 & +0.6 \\
Mean & +1.10 & -0.33 & +0.27 \\
Bird 4 & +0.6 & +0.2 & 0 \\
Overall mean & +0.98 & -0.20 & +0.20 \\
\hline
\end{tabular}

more sensitive measure of performance, response latency (see for example $[10,15]$ ), however, reveals significant differential treatment effects. for each bird and each discrimination task we tabulated the median latency apartaining to all the trials including the criterion trials of the last session before the treatment (between 0.8 and $2.2 \mathrm{sec}$ ) and did the same for the relearning session (between 1 and $3.4 \mathrm{sec}$ ). The differences between these median latency pairs were then computed and are given in Table 2. The data for Bird 4 is clearly similar to that for Bird 2, though the means are shown separately with and without these scores. (Similarly calculated latency differences based on only latencies of criterion trials before and after the treatment yield an equivalent picture as those based on the whole sessions.) An analysis of variance on the data from the first 3 birds, thus retaining the advantage of the latin square dessign, indicates that the temperature treatments contribute significantly to the variance, $F(2,2)=$ $23.2, p<0.5$. An analysis of variance using all four birds (as the data for Bird 4 are not markedly different) yields an 
equivalent result $\mathrm{F}(2,6)=7.66, p<0.05$. A Sheffé test based on the latin square analysis shows the significant differences between the normal and heating treatments $(p<0.05)$, and between the normal and cooling treatments $(p<0.01)$ though the differences between cooling and heating does not quite reach significance $(p<0.1)$. It can be concluded that both experimental treatments are conducive to improved performance in these visual discrimination tasks. There is an indication that the cooling treatment was more effective than the heating treatment. The latter, however, only modified the brain temperature by approximately half as much as the former $\left(1.1^{\circ} \mathrm{C}\right.$ as against $\left.2.3^{\circ} \mathrm{C}\right)$.

\section{DISCUSSION}

The results, while demonstrating that the brain heating/ cooling method used is a viable and promising one, are only of a preliminary nature. Clearly no firm conclusions can yet be drawn about the effects of short post-acquisition brain temperature alterations on the performance of discrimination tasks during retention trials. More parameters of the treatment procedure and the discrimination task need to be explored and additional controls incorporated into the design before any interpretative discussion can be more than speculative. A more extensive monitoring of brain and body temperature and concurrent recording of electroencephalographic activity (see for example [6,12]) is also desirable. At this stage the shortening in response latencies we found after both cooling and heating could be ascribed to either a delayed increase in motor activity or retrieval efficiency, or an improvement in ongoing information storage or a combination of these processes arising either through changes in neural arousal or metabolism.

\section{ACKNOWLEDGMENT}

We wish to thank Mr. D. Harper for assistance with the histology. The research was supported by a grant from the Science Research Council (London) to J. D. D.

\section{REFERENCES}

1. Alloway, T. M. Effects of low temperature upon acquisition and retention in the grain beetle (Tenebrio molitor). J. comp. physiol. Psychol. 69: 1-8, 1969.

2. Beitel, R. E. and P. B. Porter. Deficits in retention and impairments in learning induced by severe hypothermia in mice. $J$. comp. physiol. Psychol. 66: 53-59, 1968.

3. Deutsch, J. A. (ed.) The Physiological Basis of Memory. London: Academic Press, N.Y., 1973.

4. Fischer, G. J. Arousal and impairment: temperature effects on following during imprinting. J. comp. physiol. Psychol. 73: 414-420, 1970.

5. Hockey, G. R. J., S. Davies and M. M. Gray. Forgetting as a function of sleep at different times of day. Q.J. exp. Psychol. 24: $386-393,1972$

6. Horsten, G. P. M. The influence of body temperature on the electroencephalogram. Acta. brev. néerl. Physiol. 17: 23-25, 1949 ,

7. Jacobs, B. L. and C. A. Sorenson. Memory disruption in mice by brief post trial immersion in hot or cold water. J. comp. physiol. Psychol. 68: 239-244, 1969.

8. Karten, H. J. and W. Hodos. A Stereotaxic Atlas of the Brain of the Pigeon (Columba livia). Baltimore: Johns Hopkins, 1967.
9. McNamara, M. C. and M. L. Riedsel. Memory and hibernation in Citellus Lateralis. Science 179: 92-94, 1973.

10. Milner, A. D. and G. Ettlinger. Response latencies in go, no-go discrimination performance by monkeys. Neuropsychologia 10: $375-378,1972$.

11. Mrosovsky, N. Lowered body temperature, learning and behaviour. In: Mammalian Hibernation, edited by K. C. Fisher. Edinburgh: Oliver and Boyd, 1967.

12. Ookawa, T. Electrophysiological observations during body cooling and rewarming in young chickens. Poultry Sci. 52: 1019-1029, 1973.

13. Rautenberg, W., R. Necker and B. May. Thermoregulatory responses of the pigeon to changes of the brain and the spinal cord temperatures. Pflügers Arch. ges. Physiol. 338: 31-42, 1972.

14. Sudak, F. N. and W. B. Essman. Impairment of retention as a function of post conditioning hypothermia. Fedn Proc. 21: $225,1962$.

15. Sutherland, N. S. and N. J. Mackintosh. Mechansims of Animal Discrimination Learning. New York-London: Academic Press, 1971. 